\title{
ESCOLA, LUGAR DO DESRESPEITO: INTOLERÂNCIA CONTRA RELIGIÕES DE MATRIZES AFRICANAS E ESCOLAS PÚBLICAS BRASILEIRAS
}

\author{
SCHOOL, A PLACE OF DISRESPECT: INTOLERANCE AGAINST AFRICAN \\ RELIGIONS IN BRAZILIAN PUBLIC SCHOOLS
}

\author{
1Thula Rafaela de Oliveira Pires \\ ${ }^{2}$ Gianna Alessandra Sanchez Moretti
}

\section{RESUMO}

As escolas têm sido um lugar privilegiado de violência para negros no Brasil. A partir do tratamento contingente da liberdade religiosa, pretende-se denunciar a relação perversa entre intolerância religiosa e racismo, e como isso tem impactado na rotina de adolescentes e crianças em escolas públicas no Brasil. Com a sistematização do marco normativo contra a discriminação religiosa nas escolas pretende-se reafirmar o compromisso da democracia brasileira com a liberdade e com a educação orientada ao respeito, autonomia e emancipação.

Palavras-chave: Intolerância religiosa, Racismo, Direito à educação

\begin{abstract}
Schools have been a privileged place of violence for blacks in Brazil. Starting from the contingent treatment of religious freedom, this article aims to denounce the perverse relationship between religious intolerance and racism, and how it has impacted the routine of children and adolescents in public schools in Brazil. The analysis of the systematization of the normative framework against religious discrimination in schools intends to reaffirm the commitment of Brazilian democracy with freedom and an education oriented towards respect, autonomy and emancipation.
\end{abstract}

Keywords: Religious intolerance, Racism, Right to education

\footnotetext{
${ }^{1}$ Doutora em Direito Constitucional e Teoria do Estado pela Pontifícia Universidade Católica - PUC, Rio de Janeiro (Brasil). Professora nos Cursos de Graduação e Pós-Graduação do Departamento de Direito da PUC, Rio. E-mail: tutortreinamento@gmail.com

${ }^{2}$ Doutoranda em Direito pela Universidade de Brasília - UNB, Distrito Federal, (Brasil). Bolsista em Gestão de Sistemas de Conhecimento pela United Nations Institute for Training and Research - UNITAR, Suiça. E-maul: tutortreinamento@gmail.com
} 


\section{INTRODUÇÃO}

Para crianças e adolescentes negros no Brasil, a escola tem sido um lugar privilegiado de violência. O racismo institucional que desencadeia essa realidade é o mesmo fenômeno que faz com que agentes públicos atuem orientados por uma visão etnocêntrica de mundo, impondo uma epistemologia que desqualifica o diferente, desvaloriza formas de vida e identidades. Todos aqueles que se afastam do padrão do homem, branco, de origem europeia, proprietário, cristão e heteronormativo estão mais sujeitos a sofrer humilhações e violências corretivas, veladamente autorizadas por uma sociedade que convive com o racismo, o patriarcado, a homofobia, o eurocentrismo e outras formas de desrespeito.

Trata-se de uma realidade conhecida, mas que insiste em ser invisibilizada e desconsiderada por muitos dos que se dizem comprometidos com a liberdade religiosa e com o desenvolvimento de um modelo de educação livre, crítico e respeitoso. O Direito e a Educação representam áreas do conhecimento autônomas, com princípios e reflexões próprias, mas enquanto mecanismos de controle social atuam na determinação de padrões sociais de respeito.

Este artigo visa estreitar as trocas entre essas áreas, principalmente através da relação entre racismo e intolerância religiosa. Fala-se em intolerância, mas para além da manutenção de uma postura de suposta superioridade daquele que 'tolera', as reflexões propostas orientamse ao reconhecimento mútuo e, nesse sentido, tolerância e condescendência são insuficientes.

Acredita-se que as discussões sobre intolerância religiosa devem ser compreendidas a partir do tratamento contingente da liberdade religiosa. A indicação abstrata do conceito de liberdade religiosa tende a promover uma análise supostamente neutra do referido valor, que encobre parcela importante dos fatores que inviabilizam sua real fruição pelos grupos politicamente vulneráveis da sociedade. Nesse sentido, pretende-se retomar os contornos que foram atribuídos aos conceitos de liberdade religiosa, laicidade e secularização no início da República brasileira. Em seguida, serão destacadas as relações entre intolerância religiosa e racismo. Por fim, objetiva-se concretizar o problema enfrentando no recente caso de intolerância religiosa contra estudante de escola pública do Município do Rio de Janeiro, que aos 12 anos foi impedido pela diretora de entrar na escola, em virtude de uma bermuda branca e fios de contas sob o uniforme.

A parte final do artigo dedica-se a sistematizar o marco normativo contra a discriminação religiosa nas escolas. A intolerância contra religiões de matrizes africanas é 
inconstitucional e ilegal, e resulta em violação de múltiplos direitos fundamentais, o direito à educação e à liberdade religiosa. Serão apresentadas normas que proíbem a discriminação religiosa e destacados os limites e desafios para sua efetividade, bem como afirmados os princípios que devem nortear um modelo de educação comprometido com a emancipação, o respeito, a dignidade e a liberdade.

\section{Da LAICIDADE AO ESTUdO CONFESSIONAL: A CONSTRUÇÃO DA NOÇÃO DE LIBERDADE RELIGIOSA NO BRASIL}

A compreensão acerca do conceito jurídico de liberdade religiosa que orienta esse trabalho é construída a partir das noções de liberdade de crença e liberdade de culto. A liberdade de crença refere-se ao direito de exprimir, de externar e de se autodeterminar a partir de uma crença, bem como a possibilidade de não ter ou professar qualquer perspectiva religiosa. A liberdade de culto também representa uma forma de manifestação exterior da religião professada, mais diretamente orientada à proteção dos atos/ritos/liturgias próprios da religião.

A proteção constitucional conferida à liberdade religiosa determina que sua aplicação seja orientada pela afirmação da cidadania, dignidade humana e pluralismo político, além de estar atrelada à consecução dos objetivos da República brasileira, consubstanciados no artigo $3^{\text {o }}$ da Constituição Federal. Os fundamentos constitucionais impedem que o conceito seja apropriado por algumas concepções de mundo, excluindo outras tantas possíveis, e que venha a ser usado para legitimar violências e desrespeito. A ênfase conferida pelo Constituinte de 1987/1988 pretende responder ao uso discriminatório e seletivo que tradicionalmente o direito brasileiro e a história político-constitucional pátria conferiram ao conceito.

A primeira Constituição brasileira, promulgada em 1824 como estatuto político da Independência, estabeleceu um Estado confessional. A religião católica apostólica romana foi declarada religião oficial do Império e representava a única forma de culto admitida nos espaços públicos, conforme artigo $5^{\circ}$.

Mais do que o reconhecimento formal pelo Estado de uma determinada forma religiosa, houve a imposição de um projeto político colonizador. Uma das maneiras mais eficientes de manter a dominação é impor uma imagem depreciativa aos dominados (FANON,

2010). Dessa forma, a sua libertação fica condicionada a um processo lento e difícil de modificação desta autoimagem distorcida. Para garantir a afirmação dos valores do homem 
branco, europeu, cristão, proprietário e heterossexual, além de obrigar os escravos a se converterem, promoveram a satanização dos seus rituais e prenderam os mais 'insistentes'. Tudo que dizia respeito ao negro ou era perversamente depreciado ou se transformava em conduta criminosa. (PIRES, 2013)

De um lado, os institutos que subordinavam a igreja ao poder civil seguiam a estrutura pombalina (LEITE, 2011), estabelecida no período colonial e que determinava que as autoridades eclesiásticas católicas dominassem a educação, a saúde pública, as obras assistenciais e tinham exclusividade na concessão de registros de nascimento, casamento e óbito. De outro, as confissões acatólicas sofreram perseguição como a obrigação de que os cultos acatólicos fossem ministrados somente para estrangeiros e na língua deles; a recusa em abrigar corpos acatólicos em cemitérios sob administração eclesiástica; a equiparação dos matrimônios evangélicos a concubinatos; a criminalização do culto de religião diferente da oficial, da zombaria contra a religião oficial e de manifestações públicas de ideias contrárias à existência de Deus, além de estabelecer pena de morte para quem cometesse o crime de 'feitiçaria'.

Com a proclamação da República em 1889, a adoção da forma de Estado Federativa, a abolição da escravidão, o fỉm do voto censitário e o reconhecimento da proteção constitucional das liberdades, as relações entre Estado e religião sofreram alterações significativas. Por exemplo, a edição do Decreto 119-A, em 07 de janeiro de 1890, proibiu a intervenção da autoridade federal e dos Estados membros em matéria religiosa, consagrou a liberdade de culto, extinguiu o padroado, reconheceu personalidade jurídica a igrejas e demais confissões religiosas. Com a separação entre Estado e igreja, foi possível secularizar os cemitérios públicos, instituir o casamento civil e o ensino religioso leigo, além de erigir a liberdade de culto e de associação religiosa a direito fundamental.

Ainda assim, a República criminalizou o espiritismo e o curandeirismo, tratando religiões afro-brasileiras como questão de 'Segurança Pública'. A leitura da liberdade religiosa feita a partir de uma lente que reconhecia respeito apenas a tradição cristã fica evidenciada em trechos de Rui Barbosa (1981), no Discurso no Colégio Anchieta: “o Brasil nasceu cristão, cresceu cristão, cristão continua a ser até hoje. [...] se a República veio organizar o Brasil, e não esmagá-lo, a fórmula da liberdade constitucional, na República, necessariamente há de ser uma fórmula cristã". 
Foi através dessa lente que se constituiu a laicidade brasileira, que deveria representar a emancipação do Estado e do ensino público, a desvinculação confessional das instituições políticas, a pretensa neutralidade do Estado em matéria religiosa ou, ao menos, a concessão de tratamento estatal isonômico às diferentes agremiações religiosas. No entanto, acabou por constituir uma regulação política, jurídica e institucional entre religião e política, igreja e Estado que atribuía hierarquias morais entre concepções cristãs e as demais, algumas das quais sequer alçadas ao status de religião, como as religiões de matrizes africanas tradicionalmente referenciadas pejorativamente como seitas e feitiçaria.

A Constituição de 1934 manteve a separação formal entre igreja e Estado, mas acrescentou a possibilidade de colaboração entre esses dois poderes e introduziu: a criação de feriados religiosos; o reconhecimento dos efeitos civis do casamento religioso; a permissão da manutenção de cemitérios particulares; a inclusão da disciplina religiosa nas escolas e o serviço militar alternativo para os eclesiásticos. Havia ainda previsão para o ensino religioso confessional facultativo nas escolas públicas (artigo 153) e o estímulo à educação eugênica (artigo 138). Mais uma vez, o uso da religião se impôs como importante mecanismo de controle social e legitimação de projeto político, realidade representada simbolicamente pela construção da estátua do Cristo Redentor como um dos principais monumentos da capital brasileira. A Constituição de 1937 consolidou, em grande medida, o tratamento conferido pelo ordenamento anterior.

Na década de 30 foi institucionalizada a Umbanda, a partir da organização em 1939, no Rio de Janeiro, da União Espírita de Umbanda do Brasil (LEITE, 2014). A afirmação de religiões de matrizes africanas gerou não apenas o recrudescimento dos processos de criminalização da cultura negra como também sua desvalorização em relação ao próprio espiritismo, através da sua vinculação com a expressão ‘baixo espiritismo'.

Emerson Giumbelli (2003) avalia a utilização desta categoria durante a primeira metade do século XX. Representando a população negra o perfil do inimigo para os órgãos de persecução penal, a referência à categoria 'baixo espiritismo' nos documentos policiais e sentenças demonstra a postura desses órgãos em identificar essas práticas espíritas como fraudulentas.

O processo de redemocratização que se cristalizou na Constituição de 1946 não gerou alterações importantes no tratamento formal da liberdade religiosa. Normas relacionadas à secularização dos cemitérios; proteção jurídica das associações religiosas; representação 
diplomática junto á Santa Sé; ensino religioso confessional e facultativo e as relativas ao casamento civil foram similares às existentes na Constituição de 1934. Destaca-se nesse momento a atuação do constituinte Caires Brito, preocupado com a continuidade dos atos de violência contra as religiões negras, caracterizados por perseguição, invasão de terreiros, espancamento e prisões abusivas de seus adeptos (Scampini, 1974, p. 182). Sua proposta pretendia eliminar da redação do artigo $141 \S 7^{\circ}$ a expressão "desde que não contravenham à ordem pública ou aos bons costumes", que amparava arbitrariedades, mas foi rejeitada.

A Constituição de 1967 e Emenda de 1969 mantiveram o mesmo tratamento conferido pelos ordenamentos constitucionais a partir de 1934. Para garantir o livre exercício dos cultos africanos em seu território, o Estado da Paraíba, em 1966, aprovou a Lei n 3443 que vinculava a realização dos cultos à autorização da Secretaria de Segurança Pública. Para realizar suas atividades as casas religiosas deveriam regularizar-se civilmente e os responsáveis pelos cultos deveriam fazer prova de idoneidade moral e de 'perfeita sanidade mental', consubstanciada em laudo psiquiátrico. O seu caráter flagrantemente discriminatório foi objeto de questionamento junto ao Supremo Tribunal Federal, através da Representação de Inconstitucionalidade 959-9, julgada em 1985. Trechos do relatório são representativos do racismo institucional dos Poderes Executivo e Judiciário e do desrespeito no tratamento das religiões de matrizes africanas, sempre recorrendo a proteções universais e retóricas de igualdade formal e liberdade. (PIRES, 2013).

A Constituição de 1988 oferece dispositivos que protegem a liberdade religiosa e seus postulados, estabelece a laicidade do Estado brasileiro, admite a promoção de ensino religioso em escolas públicas, entre outros. Trata-se de um conjunto normativo que pode ser interpretado seletivamente, mas que não inviabiliza uma aplicação diametralmente oposta ao retrato que se acabou de enunciar.

No entanto, episódios como a manutenção de símbolos religiosos em órgãos públicos (crucifixos, por exemplo) e a assinatura do acordo bilateral entre o Brasil e a Santa Sé em 2009 denotam a continuidade do tratamento preferencial à tradição cristã. Os casos de intolerância contra religiões de matrizes africanas continuam fazendo parte da realidade brasileira, não apenas através da atuação de pessoas e instituições religiosas, como também dos agentes e instituições públicas. 


\section{INTOLERÂNCIA RELIGIOSA E RACISMO}

De acordo com Schwarcz (1996) a atribuição de inferioridade e teor pejorativo ao negro e a tudo que lhe possa ser diretamente associado encontra amparo formal no Brasil no final do século XIX. A tese da autora é de que as teorias raciais passaram a ser adotadas em larga escala no Brasil nos anos 1870. Instituições de pesquisa e ensino brasileiras como o Instituto Histórico e Geográfico Brasileiro (IHGB), as Faculdades de Direito de Recife e São Paulo e as Faculdades de Medicina do Rio de Janeiro e Bahia elegeram o darwinismo social como modelo mais adequado de compreensão da sociedade.

Com o darwinismo social, a 'diferença' passou a ser qualificada racialmente. Nesse modelo, os sujeitos eram tratados a partir dos elementos físicos e morais da raça a qual pertenciam. O discurso liberal relegou a ideia de igualdade ao plano abstrato e passou a afirmar hierarquias entre seres humanos, houve o enaltecimento de 'tipos puros' e a miscigenação representava degeneração racial e social.

Essas teses ganharam destaque no mesmo momento em que se fortaleceu o debate sobre a abolição da escravidão e continuaram a nortear o imaginário social mesmo depois de seu adimplemento. A modernização brasileira ficou condicionada a uma realidade racial branca, o teve sua imagem assinalada como representativa dos principais males da sociedade brasileira. Além de preguiçosos, degenerados, depravados sexuais e incivilizados, ganharam entre os intelectuais brasileiros a pecha de criminosos e responsáveis pelo enfraquecimento biológico da população.

O processo de construção da subjetividade do negro realizou-se a partir: 1) de uma imagem distorcida sobre si mesmo que promove a internalização de noções de inferioridade e subalternização, difíceis de serem revertidas; 2) de uma crença na necessidade de negação de suas referências de pertencimento racial (embranquecimento) como condição de aceitação e mobilidade social; 3) da assimilação de um ideário que coloca no negro a responsabilidade pelas desigualdades raciais. (PIRES, 2013).

O olhar sobre a miscigenação começou a ser alterado a partir dos anos 1930, com grande influência da interpretação do Brasil feita por Freyre em Casa Grande e Senzala. A mestiçagem passou a definir o brasileiro e a cordialidade entre as 'três raças' passava a ser entoada como mantra da unidade nacional. Esse ideário, de uma 'democracia social e étnica' ancorava-se nas seguintes premissas: a) o Brasil nunca conheceu o ódio entre raças (preconceito racial); b) as linhas de classe não eram rigidamente definidas a partir da cor; c) 
os mestiços se incorporavam lenta, mas progressivamente à sociedade e à cultura nacionais; d) os negros e os africanismos tendiam paulatinamente a desaparecer, dando lugar a um tipo físico e a uma cultura propriamente brasileiros (GUIMARÃES, 2004, p. 16).

Contrariamente à percepção do Brasil como laboratório de cooperação racial, os cientistas que participaram do Projeto UNESCO, entre 1950 e 1970, denunciaram o racismo da sociedade brasileira. Nas décadas de 50 e 60 destacaram-se os trabalhos que denunciavam o descompasso entre a sociedade industrial e a distribuição material e simbólica do período escravista. O ‘racismo' se consolidou como conceito analítico na década de 70.

Hasenbalg demonstrou que a cor poderia ser considerada como variável independente para explicação das desigualdades de renda e escolaridade, destacando o 'ciclo cumulativo de desvantagens dos negros'. Ele destaca a estreita conexão entre educação e desigualdades raciais, gerada tanto na fase preparatória de educação formal como no ingresso ao mercado de trabalho (1997). O autor lembra que muitos ativistas e educadores apontam como causa dessa discriminação o preconceito existente no conteúdo curricular, principalmente nos livros didáticos. Em sua opinião, o maior problema está nos estereótipos dos professores a respeito da educabilidade das crianças negras e pobres, o que representa um dos principais mecanismos de transmissão intergeracional das desigualdades raciais.

A intolerância contra religiões de matrizes africanas, o genocídio da população negra jovem, discursos de ódio contra negros, a reprodução de uma epistemologia que os infantiliza e deprecia, a erotização de seus corpos traduzem, entre outros exemplos, um modelo de sociedade que se constitui e naturaliza uma hierarquia entre seres humanos que estabelece o respeito a partir dos fenótipos e características culturais identificados como brancos.

\section{O DESRESPEITO ÀS CRIANÇAS DE AXÉ ${ }^{1}$ NO ENSINO PÚBLICO BRASILEIRO}

No dia 25 de agosto de 2014, na Escola Municipal Francisco Campos (Grajaú, Rio de Janeiro), um estudante de 12 anos da $4^{\text {a }}$ série do ensino fundamental, foi impedido de entrar na escola pela diretora, por estar usando roupas 'fora do padrão adequado'. Nas palavras do menino: "ela falou que eu não ia entrar e botou a mão no meu peito" (MACHADO, 2014).

\footnotetext{
${ }^{1}$ A expressão "crianças de axé" faz referência aos adeptos de casas religiosas de matrizes africanas. Toma-se a perspectiva de "casas de axé" como espaços privilegiados de resistência cultural, política, social e religiosa de matriz afro-brasileira e inseridas em sua tradicional luta por equidade racial. (FONSECA e GIACOMINI, 2013).
} 
Pelos relatos da mãe: "na porta da escola, ela [diretora] não viu que eu estava atrás e colocou a mão no peito dele e disse: Aqui você não entra. E eu expliquei que ele teria que usar as guias e o branco por três meses e aí ela respondeu: o problema é seu" (Idem).

O estudante, que há um mês cumpria obrigações religiosas do candomblé, usava bermuda branca, fios de conta sob o uniforme e boné branco. Segundo a sua mãe: "Antes de ele entrar para o candomblé, eu avisei para a professora e ela logo disse que ele não entraria no colégio. Eu expliquei que ele teria que usar branco e as guias, mas ela não aceitou" (MENDONÇA, 2014).

Em razão dessa postura institucional e da obrigação religiosa, o estudante perdeu um mês de aula. No dia do incidente, quando tentou voltar a frequentar as aulas, a diretora cumpriu a advertência e impediu sua entrada, na presença de sua mãe e de outros estudantes (MOURA e CUNHA, 2014). Após o fato, o estudante que estava nessa escola há oito meses pediu transferência para a unidade que estudou anteriormente, a Escola Municipal Panamá.

O caso ganhou destaque nos noticiários, houve manifestação na frente da escola por grupo inter-religioso (MOURA, 2014) e o prefeito da cidade do Rio de Janeiro formalizou pedido de desculpas à família, em audiência com o jovem, sua mãe, seu advogado e a Secretária de Educação. Nas palavras do Prefeito: “A mensagem que queremos passar é de que não há qualquer preconceito na rede municipal de ensino e nem na escola, que está entre as melhores da cidade" (MENDONÇA, 2014).

Apesar da fala do Prefeito, Eduardo Quintana (2013) apurou em entrevistas a professoras filhas de santo que trabalham nas redes municipal e estadual de ensino do Rio de Janeiro exemplos contundentes de intolerância contra religiões de matrizes africanas, institucionalmente identificadas. Eloisa, professora de Biologia, afirma que a Secretaria Municipal de Educação proíbe a divulgação de atitudes de intolerância nas escolas da rede e que foi proibida pela direção da escola em que trabalha de afixar cartazes sobre a caminhada contra a intolerância religiosa (QUINTANA, 2013). Maria das Graças, professora de Educação Artística, destaca a falta de respeito das escolas em relação às necessidades dos estudantes praticantes das religiões afro-brasileiras, caracterizadas em frases como "Quem mandou ele(a) fazer o santo?" (Ibid., p. 135).

O caso em comento recebeu uma interpretação padrão pela autoridade policial que, assim como nos casos de racismo, tende a lidar com a intolerância contra religiões de matrizes africanas de modo a tipificá-las de maneira branda e descaracterizada. O convencimento do 
delegado, que tipificou a conduta como 'Constrangimento' (artigo 232, Lei 8069/90), fez com que o Poder Judiciário analisasse o caso via Juizado Especial Criminal.

Após ouvir testemunhas, responsáveis pela escola e pelo menor, opinou o Ministério Público que a conduta discutida não era de Constrangimento, mas de ofensa ao artigo $6^{\circ}$ da Lei 7.716/89: "recusar, negar ou impedir a inscrição ou ingresso de aluno em estabelecimento de ensino público ou privado de qualquer grau”. No mesmo sentido prolatou a sentença o juiz do Processo 0377161-20.2014.8.19.001, encaminhando-o para Vara Criminal, em razão da incompetência do Juizado para condutas de maior potencial ofensivo.

Nos autos do referido processo, a mãe do ofendido relata que quando foi avisar sobre a necessidade de o filho faltar algumas aulas por motivação religiosa, teria ouvido a diretora dizer na sala ao lado que o estudante não entraria de branco, nem com nada de macumba. Em sua defesa, a diretora e suas testemunhas alegam que sua única ação foi impedir a entrada do estudante sem uniforme. Sob o suposto manto da neutralidade do uniforme, o educador responsável pela escola pública se exime de avaliar as circunstâncias que envolvem o estudante sob sua responsabilidade e impede a sua entrada.

Ainda que se pretenda considerar, como o delegado responsável pelo caso, que não houve motivação religiosa no ato praticado pela diretora, seu eco corresponde ao comportamento padrão dedicado aos adeptos de religiões de matrizes africanas nas escolas públicas. Comportamentos caracterizados por relatos como o de Vera Covas que contou que a professora de seus netos de 13 e 12 anos, praticantes do candomblé, "passava óleo ungido na testa dos alunos para que todos ficassem mais tranquilos e para tirar o Diabo de quem fosse do candomblé" (CAPUTO, 2012, p. 197). Assim como pela fala de Jailson dos Santos que declarou que não se sentia discriminado na escola, “a não ser aquele preconceito normal [...] de me chamarem de macumbeiro e de acharem que macumbeiro sempre está pronto para fazer mal para alguém. [...] Não falo que sou do candomblé. Se ninguém souber, ninguém discrimina" (Ibid., p. 201).

Jailson e sua irmã estudaram na Escola Estadual Ary Tavares, em Nilópolis, na Baixada Fluminense, Estado do Rio de Janeiro. Stela Caputo, em 1996, acompanhou um conselho de classe na referida escola e, ao final, conversou com os 14 professores presentes. Uma das entrevistadas afirmou:

Não temos crianças com esse 'problema' aqui na escola, a maioria é católica. Cinco professores afirmaram que acham 'um absurdo' que crianças pratiquem candomblé. [...] 
Perguntei ao grupo o que achavam da discussão da lei do Ensino Religioso e se eles aprovavam essa disciplina para as escolas. Treze professores responderam que sim, desde que excluísse 'seitas', como a 'macumba'. O que deve ser ensinado é o catolicismo e as religiões evangélicas, [...] outra entrevistada [...] disse que tentaria tirar essa 'ideia de macumba' da cabeça de qualquer aluno seu. Perguntei como ela pretendia fazer isso. Lendo a Bíblia todos os dias na escola, respondeu. [grifos no original]. (Ibid., p. 204)

Trata-se de uma violência difícil de ser superada, por ser exercida em idade precoce, por pessoas e instituições que exercem sobre a vítima indiscutível relação de poder. Essas circunstâncias se agravam nas instituições que oferecem seletiva e de maneira discriminatória o ensino confessional, encoberto pelo aspecto facultativo descrito na lei e pelo não oferecimento de confissões que contemplem a realidade religiosa dos estudantes.

O desrespeito vivenciado por crianças de axé nas escolas brasileiras está profundamente enraizado no modelo de laicidade que por aqui se construiu. $\mathrm{O}$ manto da neutralidade, universalidade do direito e dos "uniformes" tem servido para escamotear estruturas de poder que elegem alguns valores (no caso citado, cristãos) como moralmente superiores e válidos, em detrimento de outras visões de mundo e formas de vida. Com uma só conduta são violadas duas dimensões fundamentais da construção da autonomia: a liberdade religiosa e o direito à educação.

\section{O MARCO NORMATIVO CONTRA A DISCRIMINAÇÃO RELIGIOSA NA ESCOLA}

O Brasil é um Estado providência e laico, portanto, tem um sistema normativo que garante o respeito e a igualdade e proíbe a discriminação de qualquer natureza. A seguir, serão destacadas disposições relevantes de instrumentos normativos orientados a esse fim, de modo a identificar as oportunidades e os limites que eles oferecem para os titulares de direitos e portadores de deveres frente a discriminações com fundamento racial/religioso na escola.

A Constituição Federal de 1988 elenca como objetivos da República brasileira: "construir uma sociedade livre, justa e solidária"; "erradicar a pobreza e a marginalização e reduzir as desigualdades sociais e regionais"; e "promover o bem de todos, sem preconceitos de origem, raça, sexo, cor, idade e quaisquer outras formas de discriminação" (artigo $3^{\circ}$ ). Garante, ainda, que "todos são iguais perante a lei, sem distinção de qualquer natureza, garantindo-se aos brasileiros e aos estrangeiros residentes no País a inviolabilidade do direito à vida, à liberdade, à igualdade, à segurança e à propriedade" (artigo $\left.5^{\circ}\right)$. Prevê que a liberdade 
de consciência e de crença é inviolável e assegura o livre exercício dos cultos religiosos (artigo $\left.5^{\circ}, \mathrm{VI}\right)$ e que "ninguém será privado de direitos por motivo de crença religiosa ou de convicção filosófica ou política” (artigo 5º VIII).

Fundada nesses princípios, a Lei 12.288 de 20 de julho de 2010 estabelece que a liberdade de consciência e de crença é inviolável, assegura o livre exercício dos cultos religiosos e garante a proteção aos locais de culto e a suas liturgias (artigo 23). A referida lei institui o Estatuto da Igualdade Racial, com o objetivo de "garantir à população negra a efetivação da igualdade de oportunidades, a defesa dos direitos étnicos individuais, coletivos e difusos e o combate à discriminação e às demais formas de intolerância étnica" (artigo $1^{\circ}$ ).

$\mathrm{O}$ direito à liberdade de consciência e de crença e ao livre exercício dos cultos religiosos de matriz africana é definido em detalhe no artigo 24 da Lei 12.288. A "assistência religiosa aos praticantes de religiões de matrizes africanas internados em hospitais ou em outras instituições de internação coletiva" é garantida no artigo 25. No plano das políticas públicas, a Lei estabelece que o "poder público adotará as medidas necessárias para o combate à intolerância com as religiões de matrizes africanas e à discriminação de seus seguidores" (artigo 26).

No âmbito específico da educação, a Constituição Federal considera a educação um direito social fundamental (artigo $6^{\circ}$ ) e um "direito de todos e dever do Estado e da família" (artigo 205). Para o Estado brasileiro, a função da educação, que requer a colaboração da sociedade, visa o pleno desenvolvimento da pessoa, seu preparo para o exercício da cidadania e sua qualificação para o trabalho. O Brasil tem o dever de promover a educação escolar pública (artigo $4^{\circ}$, Lei 9.394 de) e de ministrar o ensino com base na "igualdade de condições para o acesso e permanência na escola" (artigo 206, Constituição Federal).

A carta constitucional também estabelece como o Estado deve prestar o direito à educação (artigo 208). Por exemplo, a educação básica é obrigatória e gratuita dos quatro aos dezessete anos de idade, inclusive para os que não tiveram acesso na idade própria (artigo 208, I). Ele também estabelece que "o não-oferecimento do ensino obrigatório pelo Poder Público, ou sua oferta irregular, importa responsabilidade da autoridade competente" (artigo 208, $\S 2^{\circ}$ ). Qualquer cidadão pode acionar o poder público para exigir esse direito (artigo 5, Lei 9.394). Se a negligência da autoridade competente para garantir o oferecimento do ensino obrigatório for comprovada, a ela poderá ser imputado crime de responsabilidade (artigo $5^{\circ}, \S 4^{\circ}$, Lei 9.394). 
Os conteúdos mínimos para o ensino fundamental visam "assegurar formação básica comum e respeito aos valores culturais e artísticos, nacionais e regionais" (artigo 210, Constituição Federal). Para tal fim, o ensino religioso é de matrícula facultativa e "constituirá disciplina dos horários normais das escolas públicas de ensino fundamental” (§ $\left.1^{\circ}\right)$. Trata-se de um ponto bastante polêmico no que se refere à garantia da liberdade religiosa e não discriminação nas escolas, mas que constitui norma constitucional, a ser interpretada e aplicada obrigatoriamente a partir de seus princípios fundamentais.

A Lei 9.394 articula o conceito de ensino religioso estabelecendo que esse "é parte integrante da formação básica do cidadão [...] assegurado o respeito à diversidade cultural religiosa do Brasil, vedadas quaisquer formas de proselitismo" (artigo 33). Para a definição dos conteúdos do ensino religioso, a "entidade civil, constituída pelas diferentes denominações religiosas” será ouvida $\left(\S 2^{\circ}\right)$. As normas gerais da educação nacional são válidas também para o ensino privado (artigo 209, Constituição Federal).

O Estatuto da Criança e do Adolescente de 13 de julho de 1990 além de proteger o direito à educação (artigo 53), garante o "direito à liberdade, ao respeito e à dignidade como pessoas humanas em processo de desenvolvimento e como sujeitos de direitos civis, humanos e sociais garantidos na Constituição e nas leis" (artigo 15). O direito à liberdade compreende a opinião, expressão, a crença e culto religioso, entre outros (artigo 16).

A Lei 7.716 de 5 de janeiro de 1989 define "os crimes resultantes de discriminação ou preconceito de raça, cor, etnia, religião ou procedência nacional". São crimes: "recusar, negar ou impedir a inscrição ou ingresso de aluno em estabelecimento de ensino público ou privado de qualquer grau" (artigo $6^{\circ}$ ); e "praticar, induzir ou incitar a discriminação ou preconceito de raça, cor, etnia, religião ou procedência nacional” (artigo 20).

O Decreto 119-A de 7 de janeiro 1890 com vigência restabelecida em 2002, "proíbe a intervenção da autoridade federal e dos Estados federados em matéria religiosa, consagra a plena liberdade de cultos, extingue o padroado e estabelece outras providencias". Ele estabelece que todas as confissões religiosas têm igual faculdade de exercer o seu culto e regerse segundo a sua fé (artigo $2^{\circ}$ ). Além disso, cabe a todos “o pleno direito de se constituírem e viverem coletivamente, segundo o seu credo e a sua disciplina, sem intervenção do poder publico" (artigo $3^{\circ}$ ).

O Código Penal de 7 de dezembro de 1940 com vigência restabelecida em 1991 considera injúria à ofensa da dignidade ou do decoro de alguém, estabelecendo uma pena de 
detenção de um a seis meses ou multa (artigo 140). Se essa "injúria consiste na utilização de elementos referentes à raça, cor, etnia, religião, origem ou a condição de pessoa idosa ou portadora de deficiência", a pena será de reclusão de um a três anos e multa $\left(\S 3^{\circ}\right)$. Ademais, considera-se crime "o ultraje a culto e impedimento ou perturbação de ato a ele relativo", por exemplo, escarnecendo "de alguém publicamente, por motivo de crença ou função religiosa; impedir ou perturbar cerimônia ou prática de culto religioso; vilipendiar publicamente ato ou objeto de culto religioso" (artigo 208). Vale a pena notar que foi criado o "Dia Nacional de Combate à Intolerância Religiosa” (21 de janeiro) por meio da Lei 11.635 de 27 de dezembro de 2007.

Com o fim de afirmar a diversidade cultural e concretizar uma educação das relações étnico-raciais nas escolas, o Estado brasileiro adotou a Lei 10.639 de 9 de janeiro de 2003, que alterou a Lei de Diretrizes e Bases da Educação para incluir no currículo oficial da Rede de Ensino a obrigatoriedade da temática "História e Cultura Afro-Brasileira". Essa lei foi alterada ainda pela Lei № 11.645 de 10 de março de 2008, que adiciona também a história e cultura indígena. Para aplicar essas diretrizes, formulou-se o Plano Nacional de Implantação das Diretrizes Curriculares Nacionais para a Educação das Relações Étnico-raciais e para o ensino de História e Cultura Afro-brasileira e Africana.

Nota-se também o impulso que a política de educação contemporânea está tendo no Brasil, devido à entrada em vigor do Plano Nacional de Educação (PNE) para a década 20142024. A implementação de vários dos objetivos do PNE depende, direta ou indiretamente, da eliminação da discriminação e desigualdade na educação. Por exemplo, uma das estratégias das metas 2, 3 e 4 do PNE visa a "fortalecer o acompanhamento e o monitoramento [...] das situações de discriminação, preconceitos e violências na escola, visando ao estabelecimento de condições adequadas para o sucesso escolar dos alunos”.

Com base no conteúdo normativo analisado acima, pode-se concluir que o marco normativo nacional contra a discriminação racial/religiosa no Brasil é suficientemente abrangente para viabilizar a luta permanente pela promoção da igualdade e contra toda forma de intolerância religiosa e racismo. No entanto, o próprio Estado brasileiro assumiu perante o Comitê de Direitos Econômicos, Sociais e Culturais que a sociedade brasileira, ao propagar e reproduzir o mito da democracia racial, revelou-se incapaz de implementar mecanismos eficazes para incluir afrodescendentes, indígenas, indivíduos e membros de outros grupos 
discriminados na sociedade dominante (REPÚBLICA FEDERATIVA DO BRASIL, 2003, p.3).

A luta no âmbito da declaração do direito à liberdade religiosa, à educação e contra o racismo, renovada no período de redemocratização do Brasil pós ditadura militar precisa ser cotidianamente reforçada. A intolerância sofrida por adeptos de religiões de matrizes africanas expõe as continuidades de um sistema de dominação, de matriz colonial escravista, que hierarquiza seres humanos, formas de vida e privatiza espaços públicos. A despeito dos enunciados normativos acima descritos e dos embates políticos dos quais emergiram, é reproduzida a estratificação social brasileira gerada historicamente como "negócio que a uns privilegia e enobrece, fazendo-os donos da vida, e aos demais subjuga e degrada" (RIBEIRO, 2006).

\section{DIREITO À EDUCAÇÃO COMO CONDIÇÃO DE DIGNIDADE E LIBERDADE}

A educação é um direito humano fundamental, bem comum e indispensável para o exercício de outros direitos humanos. Um dos objetivos principais da educação é permitir que os indivíduos alcancem seu pleno desenvolvimento e se realizem como seres humanos, através da aquisição de conhecimentos, valores e habilidades.

A educação tem o potencial de capacitar os indivíduos a tornarem-se cidadãos autônomos e emancipados. Em sociedades capitalistas, o acesso à educação e à terra representam os bens constitutivos que mais diretamente podem interferir na redução da desigualdade e da pobreza.

O acesso a uma educação de qualidade e de cunho emancipatório pode levar à criação de oportunidades, fomentar liberdade real de escolha, crescimento econômico sustentável, melhoria das condições de saúde, mobilidade social, e prevenção de regimes autocráticos (COOMANS, 2007). A educação e a escola têm o potencial de mitigar conflitos e prevenir riscos. Portanto, elas representam ferramentas que podem melhorar a qualidade da vida humana de forma sustentável.

Porém, o direito à educação muitas vezes é reduzido à matrícula das crianças na escola (GUIMARAES-IOSIF, 2009) ou a taxas de alfabetização, enquanto elementos mais substanciais, como a formação de professores, o currículo, o desempenho, o respeito e a tolerância entre pares, e as realidades e condições dos aprendizes são colocadas de lado. A educação deve ser pensada como formação para a cidadania sem discriminação. O direito à 
educação deve pressupor o "envolvimento da escola em toda a ambiência cultural e comunitária em que está inserida" (HADDAD, 2003, p. 124).

Porém, o sistema escolar brasileiro perpetua "um sistema mantenedor de mecanismos de discriminação e exclusão" (GUIMARAES-IOSIF, 2009, p. 76). O grande desafio desse sistema é, portanto, interromper e prevenir “o desenvolvimento de uma sociedade extremamente desigual, ao invés de democrática, onde um pequeno grupo de cidadãos passa a gozar de mais direitos que a grande maioria" (Ibid., p. 85), através da emancipação de seus servidores, professores e aprendizes, baseando-se na erradicação da ignorância, do preconceito e do etnocentrismo.

Para que o direito à educação seja plenamente realizado, a educação deve buscar emancipar e refletir o diálogo entre os diferentes segmentos sociais, políticos, religiosos, etc. (PRAXEDES e PRAXEDES, 2014). O Ministério da Educação do Brasil afirma que a qualidade da educação básica visa a confrontar a desigualdade social no país e garantir a educação como um direito humano (MEC/SASE, 2014, p. 32).

Ao invés de espaços privilegiados de violência e discriminação, a escola deve combater as desigualdades e os preconceitos e fortalecer a cidadania democrática, de modo a promover uma "educação global emancipatória” fundamentada na concepção da educação em direitos humanos crítica (GUIMARAES-IOSIF, 2009, p. 83). Além da família, é na escola que se deve iniciar a "formação para a convivência com o outro não idêntico, o diferente", a qual deveria servir como um exemplo ideal da convivência na sociedade (PRAXEDES e PRAXEDES, 2014, p. 63).

Um olhar mais acurado identifica na escola a continuidade de mecanismos de violência simbólica que tiram a autoestima dos servidores, dos professores e dos aprendizes, o que os leva "ao quietismo, ao desempenho escolar ruim e à evasão escolar" (Ibid., p. 64). Para erradicar esses mecanismos perversos é fundamental a afirmação do respeito a toda forma de vida e diferença. O respeito a uma diversidade que não homogeneíza, como o mito da democracia racial, mas que afirma a pluralidade e riqueza dos diversos grupos sociais que formam a sociedade brasileira.

Além do Estado e da escola, cabe ao indivíduo emancipar-se e emancipar aos outros, aumentando o número de indivíduos "que se reconhecem como tais e não mais fazem de conta que são superiores inferiores" (RANCIÈRE, 2002, p.106). Somente um indivíduo pode emancipar outro por meio de sua própria razão (Ibid., p.108). O ambiente escolar e a relação 
mestre-aprendiz devem estar comprometidos com a erradicação da desigualdade e da discriminação e com a afirmação da emancipação; dignidade humana; igualdade; respeito à diversidade, ao multiculturalismo e às liberdades de expressão, religiosa e de culto.

\section{CONSIDERAÇÕES FINAIS}

O artigo parte da hipótese de que a escola pública, enquanto espaço de poder, tem sido um lugar privilegiado de violência e desrespeito contra adeptos de religiões de matrizes africanas, ao ecoarem o racismo constitutivo da sociedade brasileira. O legado colonial escravista, de um lado construiu um modelo de laicidade que sobrevaloriza a tradição cristã, enquanto de outro, naturalizou um modelo de estratificação social racializado e fundado na supremacia branca. A crueldade que desumaniza sujeitos e sataniza suas pré-compreensões impõe aos adeptos de religiões de matrizes africanas, sejam eles negros ou não, o desafio diário da resistência política, religiosa e cultural.

O Brasil tem um marco normativo que proíbe e criminaliza a discriminação racial/religiosa, e ao mesmo tempo permite a liberdade de consciência e de crença e assegura o livre exercício dos cultos religiosos. Tais normas são aplicáveis no âmbito escolar, podendo ser utilizadas para denunciar violações de discriminação racial/religiosa nas escolas. Além disso, tais violações também podem prejudicar o direito à educação sem discriminação. Os principais desafios para realizar esses direitos e liberdades está na utilização dessas normas pelos agentes públicos e cidadãos.

É preciso que se multipliquem mestres/cidadãos emancipadores, fato diretamente vinculado a uma formação docente de qualidade e igualmente emancipatória. Valores como emancipação, dignidade humana, igualdade, tolerância, respeito à diversidade, ao multiculturalismo, assim como à liberdade de expressão, religião e culto foram normatizados pelo ordenamento jurídico brasileiro. Além de criminalizar a discriminação racial/religiosa, garante medidas afirmativas e transformativas de promoção das liberdades e de direitos sociais, econômicos e culturais.

O Brasil deve enfrentar o fato de ter favorecido o etnocentrismo europeu e o catolicismo no conteúdo curricular; ter adotado um projeto político colonizador que satanizou outras religiões; de ser um Estado laico que mantém feriados e símbolos religiosos da tradição cristã; e de conviver com a disparidade entre a legislação formal e a aplicação dessas disposições por parte de educadores, agentes públicos, aprendizes e a comunidade escolar. 
A multiplicidade de formas de vida que produziram e constituem o povo brasileiro deve estar refletida na memória e reproduzida nas práticas sociais e educacionais com a mesma estima e consideração que desfrutou até então a elite nacional. Educação e Direito como emancipação, bem como o direito à educação que gera autonomia, só é possível com o enfrentamento permanente dessas formas de desrespeito e pela afirmação constante da dignidade, igualdade/diversidade, liberdade, cidadania e solidariedade.

\section{REFERÊNCIAS}

ALVIM, Zuleika. Imigrantes: a vida dos pobres do campo. In: SEVCENKO, Nicolau (org.). História da vida privada no Brasil. São Paulo: Companhia das Letras, 1998, v.3.

BARbOSA, Rui. Discurso no Colégio Anchieta. Rio de Janeiro: Fundação Casa de Rui Barbosa, 1981. Disponível em <http://www.icmc.usp.br/pessoas/andcarva/rb.pdf>. Acesso em: 30 mar. 2014.

CAPUTO, Stela Guedes. Educação nos terreiros: e como a escola se relaciona com crianças de candomblé. Rio de Janeiro: Pallas, 2012.

COOMANS, Fons.Content and Scope of the Right to Education as a Human Right and Obstacles to its Realization. In: DONDERS, Yvonne/VOLODIN, Vladimir. Human Rights in Education, Science, and Culture: Legal Developments and Challenges. Great Britain: MPG Books Ltd, 2007, 183-229.

FANON, Frantz. Os condenados da terra. Tradução Enilce Albergaria Rocha, Lucy Magalhães. $1^{a}$ reimpressão. Juiz de Fora: Ed. UFJF, 2010.

FONSECA, Denise Pini Rosalem da; GIACOMINI, Sônia Maria. Presença do Axé: mapeando terreiros no Rio de Janeiro. Rio de Janeiro: Ed. PUC-Rio, 2013.

GIUMBELLI, Emerson. O "baixo espiritismo" e a história dos cultos mediúnicos. In Horizontes Antropológicos. Porto Alegre, ano 9, n. 19, p.247-281, julho de 2003.

GUIMARÃES, Antonio Sergio Alfredo. Preconceito de Cor e Racismo no Brasil. In Revista de Antropologia, vol 47, no 1. São Paulo: USP, 2004.

GUIMARAES-IOSIF, Ranilce. Educação, Pobreza e Desigualdade no Brasil: Impedimentos para a Cidadania Global Emancipada. Brasília: Liber Livro, 2009. 
HADDAD, Sérgio. Direito Humano à Educação. In: BENVENUTO LIMA JR., Jayme (org.). Relatório Brasileiro sobre Direitos Humanos Econômicos, Sociais e Culturais. Brasil: Plataforma Brasileira de Direitos Humanos, Econômicos, Sociais e Culturais: 2003, 119-154. Disponível em <http://www.gajop.org.br/arquivos/publicacoes/Relatorio_Brasileiro_sobre_Direitos_Huma nos_Economicos_Sociais_e_Culturais.pdf>. Acesso em: 30 mar. 2016.

HASENBALG, Carlos. O Contexto das Desigualdades Raciais. In Multiculturalismo e Racismo: uma comparação Brasil-Estados Unidos. Jessé Souza (org.), et alii. Brasília: Paralelo 15.

LEITE, Fábio Carvalho. Estado e Religião: a liberdade religiosa no Brasil. Curitiba: Juruá, 2014.

O Laicismo e outros exageros sobre a Primeira República no Brasil. Relig. soc.[online]. 2011, vol.31, n.1, pp.32-60.

MACHADO, Mariucha. Aluno é barrado em escola municipal do Rio por usar guias do candomblé. G1. Rio de Janeiro, 02 set. 2014. Disponível em <http://g1.globo.com/rio-dejaneiro/noticia/2014/09/aluno-e-barrado-em-escola-municipal-do-rio-por-usar-guias-docandomble.html>. Acesso em: 30 mar. 2016.

MEC/SASE. Planejando a Próxima Década: Conhecendo as 20 Metas do Plano Nacional de Educação. $\quad$ Brasília: $\quad$ MEC, $2014 . \quad$ Disponível em $\langle$ http://pne.mec.gov.br/images/pdf/pne_conhecendo_20_metas.pdf $>$. Acesso em: 30 mar. 2016.

MENDONÇA, Alba Valéria. Paes pede desculpas a aluno barrado em aula por usar guias de candomblé. G1, Rio de Janeiro, 03 set. 2014. Disponível em <http://g1.globo.com/rio-dejaneiro/noticia/2014/09/paes-pede-desculpas-aluno-barrado-em-aula-por-usar-guias-decandomble.html>. Acesso em: 30 mar. 2016.

MOURA, Athos. Grupo realiza ato em frente a escola na zona norte contra intolerância religiosa. $O$ Dia, Rio de Janeiro, 09 set. 2014. Disponível em <http://odia.ig.com.br/noticia/rio-de-janeiro/2014-09-09/grupo-realiza-ato-em-frente-aescola-na-z-norte-contra-a-intolerancia-religiosa.html>. Acesso em: 30 mar. 2016. 
MOURA, Athos; CUNHA, Vania. Aluno barrado por usar guias de candomblé muda de escola. O Dia, Rio de Janeiro, 02 set 2014. Disponível em <http://odia.ig.com.br/noticia/riode-janeiro/2014-09-02/aluno-barrado-por-usar-guias-de-candomble-muda-de-escola.html> . Acesso em: 30 mar. 2016.

PIRES, Thula. Criminalização do racismo: entre política de reconhecimento e meio de legitimação do controle social dos não reconhecidos. 2013. 323 f. Tese (Doutorado em Direito Constitucional e Teoria do Estado). Orientadora: Gisele Cittadino. Rio de Janeiro: Pontifícia Universidade Católica do Rio de Janeiro, 2013.

PRAXEDES, Rosângela/PRAXEDES, Walter. Educando contra o preconceito $e$ a discriminação racial. São Paulo: Edições Loyola, 2014.

QUINTANA, Eduardo. Intolerância Religiosa na Escola: O que professoras filhas de santo tem a dizer sobre esta forma de violência. ITABAIANA: GEPIADDE, Ano 07, volume 14/ jul.-dez. 2013. pp.127-140.

RANCIÈRE, Jacques. O mestre ignorante: Cinco lições sobre a emancipação intelectual. Belo Horizonte: Autêntica, 2002.

REPÚBLICA FEDERATIVA DO BRASIL. Décimo-quarto, décimo-quinto, décimo-sexto e décimo-sétimo relatórios periódicos do Brasil ao Comitê sobre a Eliminação da Discriminação Racial. Brasília: República Federativa do Brasil, 2003. Disponível em: $<$ http://tbinternet.ohchr.org/_layouts/treatybodyexternal/Download.aspx?symbolno=CERD $\% 2 \mathrm{fC} \% 2 \mathrm{f} 431 \% 2 \mathrm{fAdd} .8 \& \mathrm{Lang}=\mathrm{en}>$. Acesso em: 30 mar. 2016.

RIBEIRO, Darcy. O povo brasileiro: a formação e o sentido do Brasil. $1^{\text {a }}$ edição. São Paulo: Companhia das Letras, 2006.

SCAMPINI, José. A Liberdade Religiosa nas Constituições Brasileiras: estudo filosóficojurídico comparado. In Revista de Informação Legislativa, p.161-203. Outubro a dezembro 1974. Disponível em < http://www2.senado.leg.br/bdsf/bitstream/handle/id/182494/000351685_5.pdf?sequence=1 >. Acesso em: 30 mar. 2016.

SCHWARCZ, Lilia. Usos e abusos da mestiçagem e da raça no Brasil: uma história das teorias raciais em finais do século XIX. In Afro-Ásia, 18. 77-101,1996. 